\title{
HISTORIA Y DEPORTE: LOS ORÍGENES DEL SURF A TRAVÉS DE LA PRENSA ESPAÑOLA ${ }^{1}$
}

\author{
Daniel Esparza
}

\begin{abstract}
The history of surfing origins in Spain is an issue rarely explored as yet. In order to go a step further, the paper explores the Spanish press to find references about surfing. The results have been crucial to know the origins of surfing in Spain: in order to fix dates, events and names. The press articles are classified by categories and all of them are listed in chronological order that could be useful as a databasis to other researchers.

Keywords: surf; history; culture; press; Spain.

Resumen: La historia de los orígenes del surf en España ha sido poco explorada. Con el fin de dar un paso más, se ha explorado la prensa española en busca de referencias al surf. Los resultados obtenidos son esenciales para conocer cómo fueron los orígenes del surf en España: fijar fechas, eventos y nombres. Se han clasificado los contenidos de los artículos de prensa por categorías, y todos han sido reunidos en una lista por orden cronológico que podrá servir de base de datos a otros investigadores.
\end{abstract}

Palabras claves: surf; historia; cultura; prensa; España.

\section{Introducción}

Quisiera dedicar esta investigación relacionada con las olas a nuestro compañero Patricio Alberto Andreaux (1955-2013), que falleció el 20 de marzo de 2013. Honda huella has dejado entre nosotros. Nunca te olvidaremos. Ojalá algún día, en otro tiempo (quién sabe dónde y cuándo) las olas te traigan de nuevo, nos traigan a todos (cuando ya no estemos ninguno), y nos reúnan otra vez, alli donde sea que eso ocurra.

¿Es el deporte relevante para el estudio de la historia? El deporte se ha convertido en un fenómeno de masas que forma parte de las estructuras culturales de las sociedades

\footnotetext{
1 Agradezco a los evaluadores anónimos y al editor de la revista por sus valiosos comentarios en la versión previa. También quisiera agradecer a José Julián «Pepe» Almoguera, Javier Gabernet, Rafael García González, Carlos Neville, Gonzalo Campa, Laura Revuelta, Carlos Beraza, Alfonso Biescas Vignau, Iñigo Letamendía, Miguel Ángel Ortega, Octavio Suárez y a Federico Romero, todos ellos pioneros del surf en España, que si bien no directamente para este artículo, sí que me han facilitado información y documentación valiosa para esta investigación general sobre la historia del surf, que en el periodo 2012-2014 estará enmarcada en el proyecto He'e nalu projekt: Identita, Historie a Literatura (Fond pro podporu védecké činnosti FF UPOL: FPVC2012/04), apoyado por la Facultad de Filosofía de la Universidad Palacký de Olomouc.
}

Romanica Olomucensia 25.1 (2013): 47-59 (ISSN 1803-4136) 
modernas. El estudio del deporte ha atraído la atención de numerosas disciplinas como la medicina, pedagogía, antropología, sociología, y la que nos interesa aquí, la historia. El deporte, y concretamente la competición deportiva, ha ido ganando terreno en las sociedades modernas y ha ido sustituyendo a la mentalidad militar de siglos anteriores, cuando el arte de la guerra era algo prioritario sobre cualquier otra cosa. ${ }^{2}$ Hoy en día las democracias nunca o casi nunca se hacen la guerra entre ellas, ${ }^{3}$ y los conflictos bélicos de antaño entre potencias europeas (como España, Francia, Alemania o Gran Bretaña) han quedado reducidos a cero desde que son democracias. De esta manera, democracia y deporte van agarradas de la mano porque ambas están sometidas a la aceptación de unas reglas y un arbitraje. En el caso de las democracias son las Constituciones las que regulan los derechos y deberes de los ciudadanos; en el caso del deporte (la competición deportiva), cada federación deportiva negocia unas reglas determinadas que todo jugador debe conocer antes de practicarlo. Ciertamente la relación deporte-democracia no quiere decir que allí donde hay deporte hay democracia, de la misma forma que allí donde hay Constitución no quiere decir que haya tampoco democracia, ya que las dictaduras también tienen sus Constituciones y sus reglas. Pero, la lógica de la competición deportiva aporta el sustrato necesario para el éxito de una democracia, al menos en el plano teórico: el respeto al otro y que las reglas de juego sean aplicadas de la misma forma para todos.

Hasta hace poco en los manuales escolares de historia, tanto de secundaria como universitarios, no se prestaba atención al deporte, sin embargo hoy en día es cada vez más usual incluir dentro de las historias nacionales los éxitos más destacados de sus deportistas, los cuales desatan la pasión y marcan el ritmo de la vida de cada Estado. Las legendarias batallas y los héroes-guerreros nacionales que suelen cubrir los libros de historia (el Cid en España, o Jan Žižka en Chequia, por poner solo dos ejemplos), están siendo sustituidos en la historia contemporánea por batallas y héroes asociados al mundo de lo deportivo. ${ }^{4}$ A veces esas «batallas deportivas» entre países encierran un alto grado de sentimiento nacional que va más allá del deporte, como el ejemplo del campeonato del mundo de Hockey hielo de 1969, que debería haberse celebrado en Checoslovaquia, pero que la invasión de la Unión Soviética unos meses antes para reprimir la Primavera de Praga (agosto de 1968) desaconsejó su celebración en dicho país. En ese campeonato, finalmente celebrado en Suecia, dos veces se enfrentaron soviéticos y checoslovacos, y las dos veces ganaron los «oprimidos». Dos victorias deportivas que trascendieron a la sociedad y que se vivieron con mucha pasión y euforia. Dos victorias que ciertamente aliviaron las tensiones que sufría la mayoría de checoslovacos en aquel entonces, aunque no sirvió para cambiar la atmósfera política de control y opresión desde Moscú. Otras veces, como ocurrió con el caso de España en 1992 y la celebración de los Juegos Olímpicos de Barcelona, el deporte sirvió para levantar la moral de un país que en el plano internacional estaba ciertamente acomplejado por su retraso científico y económico frente a las principales potencias europeas (Francia, Gran Bretaña y Países Bajos, principalmente), países que históricamente (especialmente en los siglos XVI, XVII, XVIII y XIX) habían sido sus rivales por conquistar la hegemonía del continente y del mundo. Aquellos Jue-

\footnotetext{
2 Sobre el cambio de mentalidad en el que el deporte (y la competición deportiva) sustituye a la guerra, véase: Elias y Dunning (1992).

3 Sobre la teoría de la paz democrática, entre otros véase: Maoz y Russett (1993) o Ray (1993).

4 Un ejemplo sintomático de esto lo encontramos en Chalupa (2011). En su Historia de España por fechas, incluye una buena cantidad de capítulos y «héroes» del deporte español, especialmente a partir de los JJ. OO. de Barcelona 1992, cuando se suceden grandes éxitos de gran repercusión.
} 
gos Olímpicos y todo el proceso de modernización que supuso su preparación, junto con los éxitos deportivos que se vivieron fueron un factor importante (no el único) que marcó un nuevo ímpetu en España.

\section{Metodología: antecedentes, preguntas, objetivos, fuentes y limitaciones}

El éxito y la relevancia del deporte en las sociedades modernas se pueden medir perfectamente a través de la extensa dedicación que dispensan los medios de comunicación. En España, que es el espacio geográfico en el que se va a centrar este artículo, el interés por el deporte es muy alto, hasta el punto de que el diario más leído, y con diferencia del resto, es el Marca, especializado únicamente en deportes. ${ }^{5}$

Una vez visto que el deporte es un elemento relevante de las culturas modernas y por tanto elemento destacado de la historia contemporánea, voy a explicar por qué me voy a centrar en el surf, y concretamente en los orígenes del surf en España. ¿Por qué el surf? Porque es hoy un deporte bastante popular que se practica en todas las costas del mundo donde haya olas. España no es una excepción, cuenta con casi 8.000 kilómetros de longitud de costa, y en la mayoría de sus playas, especialmente las vertientes atlántica y cantábrica -pero también en la mediterránea, donde a pesar de contar con un oleaje poco constante existe una enorme densidad de surfistas cuando se forman marejadasel surf es muy popular. Al mismo tiempo el surf es el padre de otros deportes, como el windsurf o el kitesurf, pero también de otros que se practican fuera del agua, como el skateboard y el snowboard, todos ellos inventados por surfistas, y que también tienen una gran popularidad y aceptación en el mundo. Dos de ellos son deportes olímpicos: el windsurf y el snowboard. Además, el surf es relevante porque la propia trascendencia de esta actividad acuática ha sobrepasado al deporte en sí y se ha trasladado en forma de metáfora a la sociedad moderna, con la que se ha querido narrar principalmente el éxito o el fracaso. De ahí que desde la política o desde la economía (negocios) se haya utilizado, no por casualidad, la metáfora «de saber subirse a la ola» o la de «estar en la cresta de la ola», para explicar los éxitos electorales o comerciales respectivos, o para incitar a otros a montarse en la imparable ola del éxito. Un ejemplo de este tipo de metáforas asentadas en el imaginario popular se puede observar a continuación con respecto a la nueva realidad de internet y la edición de libros, los ebooks: «La mayoría sabe que la revolución es un tsunami imparable, y algunos editores, como el de Mondadori, invitan a todos a coger la tabla de surf y subirse a la ola». ${ }^{6}$

Además de esto, el surf ha trascendido aún más en las sociedades modernas con la llegada de la revolución digital. La propia palabra «surf», en sociedades como la anglosajona o la checa, ha pasado a significar no solo el clásico de montar las olas, sino la acción más cotidiana de la revolución digital, lo que en castellano se considera «navegar» en internet: to surf en inglés, surfovat en checo.

¿Por qué investigar el surf en España? Porque los orígenes del surf en ese país no han sido lo suficientemente explorados todavía. Hasta la fecha, las pocas publicaciones existentes han estado centradas en lo local o regional: por ejemplo Gonfaus (2006) ha indaga-

\footnotetext{
5 Según la AIMC (asociación para la investigación de medios de comunicación), en su informe EGM (Estudio General de Medios), entre el periodo de febrero y octubre de 2012, el diario deportivo Marca fue leído por una media de 3.011.000 lectores diarios. En segunda posición estaba el diario generalista El País, con 1.929.000, y en tercer lugar, otro diario deportivo, el As, con 1.480 .000 lectores. Más información en www.aimc.es.

6 Mora, Miguel. «Tornado de ideas por el futuro del libro». El País, 7.6.2011, p. 40.
} 
do en los inicios del surf en la playa de Gros (San Sebastián); Echegaray y Troitiño (2007) sobre los orígenes del surf en Zarautz (Guipúzcoa); Esparza (2010) sobre los comienzos del surf en la provincia de Málaga; Pellón (2009), sobre historias del surf en Cantabria; y Carrasco y García (2011) acerca de Asturias. Pero de todos ellos, solo el que estudia la provincia de Málaga se ha llevado a cabo con la relativa rigurosidad académica que trata de contrastar fechas, lugares y acontecimientos, puesto que el resto de publicaciones se trataban de una recopilación de testimonios de pioneros basados en la memoria, en los que encontramos numerosas contradicciones, pues sobre una misma cosa, dos o más personas dan fechas, nombres, o lugares diferentes. ${ }^{7}$

Con respecto al estudio de la historia de los orígenes del surf en España, entendido como un estudio en conjunto y no solamente en cada una de sus partes, hasta donde ha llegado esta investigación solo se ha acometido uno, el de Esparza (2011), siendo todavía necesario despejar algunas incógnitas, como la de quién fue el primer surfista en España (ya que Fiochi en Santander o Cueto en Asturias son sólo dos hipótesis); además de otras incógnitas generales que descubran nuevas historias.

Teniendo en cuenta, como se ha visto, que el deporte en España tiene mucha repercusión en los medios, y que el surf ha trascendido no solo a nivel deportivo, sino que se ha instalado en el nivel de la lengua y la cultura a través de metáforas como las que he descrito anteriormente, me hago las siguientes preguntas: ¿hasta qué punto reflejó la prensa española los inicios del surf? Y, ¿hasta qué punto la prensa nos puede ayudar para escribir y fijar una historia del surf en España? Además de estas dos, hay otra pregunta más. En España el surf comenzó a evolucionar desde mediados de los sesenta, de esto hay pruebas suficientes (Esparza 2011; Pellón 2009; Carrasco y García 2011), pero teniendo en cuenta que en EE. UU. (en el continente), el surf estaba suficientemente desarrollado ya desde los años veinte, y en Inglaterra hay constancia de prácticas esporádicas de surf en la misma década: ¿se pudo haber practicado surf en España mucho antes de los años sesenta, y de haber sido así, pudo haberlo registrado la prensa española? $\mathrm{O}$, al menos, ¿pudo haber reflejado la existencia del surf fuera de España, en cuyo caso, tal vez hubiera podido inspirar a pioneros españoles a practicar el surf antes de los años sesenta?

Para contestar estas tres preguntas, que es el objetivo principal de esta investigación, voy a examinar las siguientes fuentes: Con respecto a diarios generalistas: La Vanguardia (fundado en 1881 como La Vanguardia Española) y el $A B C$ (fundado en 1903). Con respecto a diarios deportivos: El Mundo Deportivo (nació como diario en 1929, aunque desde 1906 hasta 1929 existió como semanario), el Marca (fundado en 1938) y el diario As (fundado en 1967). La búsqueda de las fuentes se realizó en la hemeroteca de la Biblioteca Nacional de Madrid. La razón de la selección de estas fuentes está en que además de ser diarios relevantes hoy en día, ya existían en los años sesenta, cuando el surf comenzó a evolucionar en España. Las fuentes que he examinado son importantes y relevantes en cantidad

\footnotetext{
Una excepción es el capítulo de Gonzalo Campa en la obra de Pellón (2009), el cual hace un excelente trabajo de recopilación de datos, muchos de ellos basados en fuentes primarias de documentos históricos, como cartas federativas, prensa local, etc. Gonzalo Campa fue el primer campeón júnior de la historia de España, en 1971, y el último presidente de la SNS (Sección Nacional de Surf), en los años ochenta, por esta razón conserva documentación privilegiada que ha compartido con el autor de este artículo. Aun con todo esto, se debe aclarar que todos los archivos que había en la SNS, en la oficina central de Madrid, desaparecieron para siempre cuando cerró la oficina, a mediados de los ochenta, debido a la crisis económica de entonces y a la reestructuración de los ministerios. Una pérdida que hace más difícil el rastreo de los orígenes y que hace más vital la búsqueda en la prensa para compensarla.
} 
y calidad, mas se debe tener en cuenta que son limitadas. En futuras investigaciones, especial atención se debería prestar al estudio de los diarios locales en las hemerotecas provinciales de las diferentes regiones del Cantábrico, de Canarias, de Cádiz y también del Mediterráneo, como Málaga o Barcelona, porque allí hay noticias en el ámbito de lo local que nunca llegaron a trascender en el nivel nacional. Ese futuro estudio deberá acometerse en equipo, pues una sola persona no podría abarcar tanto. Visto esto, y reconocidas las limitaciones, paso a explicar los pasos que voy a seguir a partir de ahora:

a) Una vez realizada la búsqueda (nivel exploratorio), el siguiente paso será:

b) Examinar todos los artículos y clasificarlos por categorías que nos ayuden a valorar la información.

c) Una vez hecho esto, describiré los contenidos generales según las categorías (nivel descriptivo).

Y, d) Finalmente con toda la información hallada en las fuentes, trataré de dar respuesta en el apartado «resultados finales» a las preguntas de investigación.

\section{Resultados cuantitativos y cualitativos de la exploración}

En total he hallado 57 artículos en el periodo 1911-1974. Anterior a 1911 no he hallado ninguno, pero posterior a 1974 otros muchos hasta nuestros días. Con el fin de limitar esta investigación, he establecido el tope en 1974, ya que el objetivo de este artículo se centra en los orígenes del surf en España, y considero que en 1974 ya se puede hablar de una consolidación del surf en dicho país, como explicaré en las conclusiones. A cada artículo le he asignado un número (por orden cronológico). La referencia completa de cada uno de los artículos (con su número correspondiente para localizarlo) la expongo al final en una lista completa, tras las referencias bibliográficas.

Una vez examinados, los he clasificado por categorías, según el contenido de la información donde aparecía el surf como deporte (no se han tenido en cuenta aquellos artículos donde se hablaba del baile surf, de moda en los sesenta, o los relacionados con el detergente de la marca Surf). Ocho han sido las categorías: a) «Información-Características»: se refiere a aquellos artículos o reportajes que dan información directa sobre qué es el surf, cómo se practica, dónde, etc.; b) «Competición»: se refiere a aquellos artículos donde se describen competiciones a nivel nacional; c) «Federación-organización»: se refiere a aquellos artículos que hablan sobre aspectos federativos y de organización a nivel nacional; d) «Premios»: se refiere a aquellos donde los surfistas son premiados a nivel nacional; e) «Daños colaterales»: se refiere a aquellos artículos donde se narra la existencia del surf como problema para los bañistas, porque reciben golpes de las tablas (núm. 17 y 53), o también positivos, porque se producen salvamentos en las playas gracias a las tablas de surf y los surfistas (núm. 48 y 54); f) «Publicidad»: se refiere a aquellos artículos publicitarios que han recogido el surf como elemento de atracción turística; g) «Espectáculo»: aquellos en los que el surf está asociado al cine (núm. 4 y 9), música (núm. 16) o famosos a los que se les asocia con el surf (núm. 45 y 57); y finalmente, h) que lo he clasificado como «Otros», y que solo ha tenido una entrada, relacionada con un ensayo periodístico sobre el mar y la vida, donde el surf y las olas se presentan como metáfora (núm. 52).

Uno de los hallazgos que ya anticipo antes de las conclusiones es que el primer artículo donde se anuncia la práctica del surf en territorio español se remonta a 1966 (núm. 14), y no tengo más remedio que anticiparlo porque este artículo me servirá como punto de 
referencia para establecer un antes y un después. Con respecto a ese antes (antes de que el surf llegara a España) esta actividad fue recogida por los diarios nacionales en trece ocasiones (ver tabla 1$){ }^{8}$

\begin{tabular}{|l|l|}
\hline \multicolumn{1}{|c|}{ Categoría } & \multicolumn{1}{c|}{ Referencia artículo núm. } \\
\hline Información-características & núm. $1,2,3,5,7,10,11,12,13=9$ artículos \\
\hline Espectáculo & núm. $4,9=2$ artículos \\
\hline Publicidad & núm. $6,8=2$ artículos \\
\hline TOTAL & 13 artículos \\
\hline
\end{tabular}

Tabla 1: Antes de la llegada del surf a España (1911-1966)

El primero de todos fue una publicación de 1911 (La Vanguardia Española), donde se narraban escenas de surf en Hawái. Se anuncia como un «nuevo deporte», y por aquel entonces la palabra surf no se usa para describir dicho deporte, sino que a esa actividad exótica venida de la Polinesia se la llamó «los montadores de olas».

De esos trece artículos solo se registraron cinco entre 1911 y 1962. Es a partir de esa fecha, 1962, cuando el surf ya se practica en Francia, ${ }^{9}$ y aparece en los diarios españoles como atracción turística de la ciudad de Biarritz, en el País Vasco francés (núm. 6). Entre 1962 y 1966, el surf aparece en ocho ocasiones, de las que seis hacen referencia al surf en Francia, algo que anticipa su inminente salto a España, al menos, con respecto al Cantábrico. De los dos restantes, uno hace referencia al surf en Honolulú (núm. 11), y el otro a Australia (núm. 12). Este último se trató de un viaje que realizó Carlos Pardo, periodista de El Mundo Deportivo, el cual había viajado hasta allí para cubrir la final de Copa Davis que disputaba el equipo nacional de tenis (con Santana como estrella) contra Australia. El periodista ya conocía el surf, porque un año y medio antes (en 1964) lo había «descubierto» en Biarritz, mientras cubría el Tour de Francia. Curiosamente, en aquella parada en Biarritz en el verano de 1964, coincidió con el equipo americano de surf, que se alojaba en el mismo hotel de la costa francesa, y tras una entrevista con el capitán, más lo que vio al día siguiente en la playa con el equipo norteamericano en las olas, consiguió reunir la información suficiente para escribir un artículo (núm. 10), que tituló «El surfing, un gran deporte que el Cantábrico podría adoptar». Así, en Australia (un año y medio después), el periodista Carlos Pardo quedó fascinado por la grandeza del surf y de lo ampliamente que estaba integrado en la sociedad australiana, hasta el punto de ser parte natural de la cultura del país. Incluso llegó a escribir que prefería la cultura surf, que la cultura «ye-ye» de los jóvenes españoles.

Una vez que el surf ha llegado a España, obviamente, se incrementa el número de publicaciones, llegando a 44 entre los años 1966 y 1974. Esas 44 publicaciones las he dividido entre aquellas que hacen referencia al surf en España, y las que lo hacen sobre lugares

\footnotetext{
8 La fecha en la que el surf comenzó en España no está clara, 1963 es la más posible. Aún así, parto en este artículo de 1966, no como la fecha en la que empieza el surf, sino como la primera vez en la que se anuncia que el surf se practica en España (en un periódico nacional).

9 Para más información sobre los orígenes del surf en Francia, véase la única obra existente al respecto: Gardiner (2004).
} 
fuera de España. Con respecto a las primeras, en la tabla 2, se puede observar el número de artículos (36) y su localización según las clasificaciones anteriormente explicadas. Los contenidos más relevantes de estos artículos los comentaré en los «resultados finales», pues son cruciales para responder a dos de las tres preguntas.

\begin{tabular}{|l|l|}
\hline \multicolumn{1}{|c|}{ Categoría } & \multicolumn{1}{c|}{ Referencia artículo núm. } \\
\hline Información-características & $\begin{array}{l}\text { núm. } 14,21,22,25,30,32,33,35,37,40,42,46,47,49,51 \\
=15 \text { artículos }\end{array}$ \\
\hline Competición & núm. $23,24,26,27,29,34,36,39=8$ artículos \\
\hline Federación-organización & núm. $31,50=2$ artículos \\
\hline Premios & núm. $41,43,44=3$ artículos \\
\hline Daños colaterales & núm. $17,48(48 b), 53,54=4$ artículos \\
\hline Publicidad & núm. $55,56=2$ artículos \\
\hline Espectáculo & núm. $57=1$ artículo \\
\hline Otros (poesía) & núm. $52=1$ artículo \\
\hline TOTAL & 36 artículos \\
\hline
\end{tabular}

Tabla 2: A partir de la llegada del surf a España (sobre España)

Con respecto a los artículos que se publicaron sobre el surf en el extranjero (ver tabla 3), fueron ocho, de los que dos dieron información extensa y detallada sobre el surf: uno sobre Hawái (núm. 28), y otro sobre piscinas de olas en Arizona (núm. 38).

De todos ellos el de Hawái es el más relevante por lo siguiente: el enviado Eduardo Criado se desplazó hasta allí para hacer una serie de reportajes sobre la exótica cultura de aquellas islas, los cuales se fueron publicando semanalmente. El tercero de ellos lo dedicó exclusivamente al surf. Y lo relevante está en que el propio enviado lo practicó por primera vez en la playa de Waikiki para escribir sobre sus experiencias. En este sentido, hasta donde ha llegado esta investigación, se trata del primer periodista en España que practicó el surf. Y lo hizo para poder narrarlo desde dentro.

El resto de artículos menciona al surf de forma breve en reportajes sobre la cultura de África del Sur (núm. 15), sobre la cultura de Australia (núm. 20) y en un artículo donde se destaca la muerte del hawaiano Duke Kahanamoku, ${ }^{10}$ padre del surf moderno, aunque el artículo mayormente está dedicado a su pasado como nadador y campeón olímpico en crawl (núm. 19). Además se registraron dos artículos sobre espectáculo, uno sobre los Beach Boys y el surf (núm. 15), y otro muy breve sobre Margarita de Dinamarca donde aparece una foto de ella con su monitor de surf en la playa (núm. 45). El último está relacionado con la publicidad y el turismo en Biarritz, donde se menciona brevemente el surf como actividad típica de ese lugar de la costa vasco-francesa.

\footnotetext{
${ }_{10}$ Más información sobre los orígenes del surf en Hawái, ver: Houston y Finney (1996) y Walker (2011).
} 


\begin{tabular}{|l|l|}
\hline \multicolumn{1}{|c|}{ Categoría } & \multicolumn{1}{c|}{ Referencia artículo núm. } \\
\hline Información & núm. $15,19,20,28,38=5$ artículos \\
\hline Espectáculo & núm. $16,45=2$ artículos \\
\hline Publicidad & núm. $18=1$ artículo \\
\hline TOTAL & 8 artículos \\
\hline
\end{tabular}

Tabla 3: A partir de la llegada del surf a España (referente a otros países)

\section{Resultados finales}

Una vez examinadas y clasificadas todas las fuentes de la exploración, procedo en esta parte final a contestar directamente las preguntas de investigación, aunque algunas ya han sido contestadas parcial o indirectamente. ¿Se pudo haber practicado surf mucho antes de los años sesenta; y de haber sido así, pudo haberlo registrado la prensa española? $\mathrm{O}$, al menos, ¿pudo haber reflejado la existencia del surf fuera de España, en cuyo caso, tal vez hubiera podido inspirar a pioneros españoles a practicar el surf antes de los años sesenta?

El hecho de que haya un apartado que se llame «antes de la llegada del surf a España», hace obvio que antes de eso no se ha registrado en la prensa ninguna actividad en territorio español. En ese periodo (1911-1966) he encontrado trece artículos. Entre 1911 y 1962, el surf apenas tuvo eco en la prensa; tan solo hubo cinco referencias a la existencia del surf. De esas cinco, en una, aparece un documento gráfico, la foto de un surfista remando una ola en California, en 1929 (núm. 3). En esas cinco referencias apenas se da información de en qué consistía esa nueva actividad (excepto en el núm. 1). Entre 1962 y 1966, se producen ya ocho referencias donde el surf aparece con más detalles, algo que pudo haber inspirado a algunos jóvenes, ya que el surf comenzó a evolucionar en España desde 1964 aproximadamente.

Con respecto a las siguientes preguntas de hasta qué punto reflejó la prensa española los inicios del surf, y hasta qué punto la prensa nos puede ayudar para escribir y fijar una historia del surf en España, una respuesta breve es que la prensa española ha aportado información muy valiosa para comprender la génesis y primeros pasos de esta actividad, cuyos contenidos esenciales, o mejor dicho una síntesis de estos, los expongo a continuación ${ }^{11}$ :

A) La prensa dejó constancia del nacimiento en 1969 de la primera estructura federativa en España, la SNS (Sección Nacional de Surf) de la que Pedro Martínez Albornoz fue su presidente (núm. 21).

B) Narró el primer campeonato celebrado en España, en 1969, en Zarautz (núm. 23), y hasta 1973 dejó artículos o notas de prensa que informaron de los sucesivos campeonatos de España. En 1970 se celebró el primer circuito de surf en España con varios campeonatos en el Cantábrico. Sin embargo, los primeros campeones de surf de España considerados así oficialmente fueron en 1971, cuando se sumaron los puntos de todos los

${ }_{11}$ Para más detalles, al final del artículo se adjunta una tabla con todas las referencias de todos los artículos para aquellos interesados que necesiten saber más. 
campeonatos celebrados, y así, en categoría sénior fue Jesús Fiochi y en júnior Gonzalo Campa, ambos de Santander. (núm. 39 y 42).

C) Las diferentes ruedas de prensa que Martínez Albornoz dio en Madrid a los medios para informar de la evolución del surf en España son ahora esenciales para conocer cómo creció el surf y en qué partes de España. Así, en 1970 había en España 10 clubes de surf y unos 150 surfistas (núm. 30, 31 y 32); en 1971 había ya 14 clubs y 194 surfistas (núm. 42); en 1972 había 16 clubes y 356 federados (núm. 50); y ya en 1973 había dos nuevos clubes federados, uno de Cádiz y otro de Las Palmas de Gran Canaria, con un total aproximado de 500 fichas federativas (núm. 51) ${ }^{12}$.

D) También nos informa de cómo practicar el surf, la técnica, y cuáles fueron los criterios para valorar a los surfistas en competición (núm. 30 y 37). Así, las puntuaciones iban de 0 a 10. Se contaban cinco olas en los 15 o 20 minutos que duraba cada manga, y luego se anulaban la mejor y la peor nota. Se puntuaba el grado de dificultad y el riesgo de cada maniobra.

E) Una vez creada la federación, España se incorporó rápidamente a las estructuras internacionales. A partir de 1969 participó en los campeonatos de Europa, siendo el mejor puesto el de Jesús Fiochi en 1970, quedando séptimo (núm. 29). También se produjo un enfrentamiento cada verano entre Francia y España, que solía servir de preparación para el europeo (núm. 36).

F) También sabemos el precio de las tablas, que en 1971 oscilaban entre las 6.000 y las 9.000 pesetas, y entre 3.000 y 4.000 pesetas de segunda mano (núm. 42). En España, en los primeros años no había industria ninguna del surf -solo algunos pioneros que fabricaban escasas tablas-, por tanto la mayoría se importaban de Francia (principalmente) y eran más caras (núm. 42). A partir de 1973, cuando ya existe una pequeña industria del surf en el norte de España (Casa Lola, en Loredo), los precios mejoran y ya se pueden encontrar por 5.000 pesetas las hechas en España (núm. 51).

G) Con respecto al léxico básico de ese nuevo deporte, como es el nombrar la herramienta básica, la tabla, o incluso el mismo deporte en sí, el surf, destaco la dificultad que tuvieron los periodistas de antaño en nombrarlos, ya que era algo que no les era familiar. Hasta 1964 no se llamó a ese nuevo deporte con el término surf. Mientras que hoy en día el léxico específico está asentado, por aquel entonces la tabla de surf recibió diversos nombres como «patinador» (núm. 3) o «plancha» (núm. 13 y 14). Y el deporte recibió varios nombres provisionales como «los montadores de olas» (núm. 1, 1911), «surfboating» (núm. 4, 1931) «navegar sobre la tabla» (núm. 5, 1949) o la versión anglosajona de entonces «surf-riding» (núm. 7, 1964), ahora también en desuso en aquella lengua.

H) Como último punto, destaco que en 1972 se registró el primer artículo escrito directamente por un surfista, en La Vanguardia Española -se trataba de Alfonso Biescas Vignau, uno de los pioneros en Zarautz-, donde escribe sobre el surf, sus experiencias y el significado para su vida y para la vida de los surfistas. Se trata de un texto que refleja el espíritu del surf y sobre todo de la época en la que se escribió, cuando todavía la densidad de surfistas en las playas era pequeña en comparación con la masificación de hoy; añado a continuación un fragmento del mismo (núm. 49):

\footnotetext{
12 Un año después, en 1974, se fundó en el Mediterráneo el Málaga Surfing Club, de la mano de Pepe Almoguera, Javier Gabernet, Rafael García González, los hermanos Gutiérrez y otros. Se trataba del primer club de surf activo en el Mediterráneo español. Más información sobre su creación en Esparza (2010).
} 
Todo aquel que empieza a hacer surf por entretenerse, probar su valor o quizá por «snobismo», no sabe que al cabo de unos pocos meses se encontrará completamente «enviciado» y que su mentalidad habrá sufrido un radical cambio hacia ideas mucho más sencillas, limpias y naturales. No volverá a ser el de antes. Comenzará a amar la naturaleza y en especial el mar, como jamás habría pensado. Verá la vida desde un punto de vista diametralmente opuesto a cómo lo había considerado hasta entonces, siendo su única preocupación real la polución de los mares, viviendo una filosofía desgraciadamente olvidada por el mundo actual. En un deporte de tan profundos sentimientos, en el que no existe la competitividad, y la rivalidad como consecuencia inmediata, es fácil imaginar la amistad que puede reinar entre sus practicantes. Por ello, para nosotros, ser surfer es una íntima satisfacción, porque el surf es más que un deporte, es un arte, una filosofía, un sentimiento, un regalo de la naturaleza.

\section{Conclusiones}

Este artículo ha trabajado casi únicamente con los datos que se han recopilado para esta investigación. Puesto que la historia del surf en España solo había producido dos publicaciones desde el mundo académico, este tercero aporta nuevas noticias y supone un avance en la materia. Este estudio ha ayudado a fijar fechas imprescindibles y datos esenciales para escribir la historia de la génesis del surf en España y su evolución, que ayudará a ordenar la información registrada en aquellas obras que han reflejado directamente el testimonio de pioneros -como las de Pellón 2009, Gonfaus 2006, Troitiño y Echegaray 2007 o Carrasco y García 2011- y, que como se dijo ya, a veces son contradictorias en las fechas, poco precisas o directamente nulas. Lo que sí se ha demostrado aquí, hasta donde ha llegado esta investigación, es que el surf ya existía en España como mínimo desde 1966, que en 1969 se organizó federativamente (con la SNS o Sección Nacional de Surf), lo que motivó que se organizaran campeonatos regularmente a partir de esa fecha. Sabemos también que el número de surfistas federados y de clubes aumentó año a año, que desde 1973 ya se fabricaban tablas para su venta en el norte de España (pequeña y primera industria del surf en España), y que la propia prensa se hizo eco de todo ello, gracias a que el presidente de la SNS, Pedro Martínez de Albornoz, emitió notas de prensa para informar de los campeonatos y convocó ruedas de prensa en el INEF de Madrid para informar sobre qué era el surf. Así pues, con todos estos datos, llego a la conclusión de que en 1973-1974 se puede dar por terminado el periodo de la génesis y formación del surf en España, para ser considerado ya un deporte consolidado con estructuras sólidas (federación, clubes e industria propia) y que hasta hoy ha ido creciendo en popularidad. Finalmente, esta investigación realiza otra aportación más al estudio de la historia del surf en España: una lista con todos los artículos hallados entre 1911-1974, la cual se adjunta tras las referencias bibliográficas, y que de facto significa una base de datos importante, hasta ahora inexistente, que facilitará el trabajo en el futuro a aquellos investigadores que quieran ir más allá de lo que se ha podido en este artículo.

\section{Bibliografía}

CAmpa, Gonzalo (2009), «Vivirlo desde los orígenes», in: Pellón, José, Historia del surfing en Cantabria, Santander: Cantabria tradicional, 57-122.

CARRASCO, Pilar - GARCíA, José R. (eds.) (2011), Cultura surf, Luanco: Museo Marítimo de Asturias.

CHALUPA, Jiři (2011), Dějiny Španělska v datech, Praga: Libri. 
Echegaray, L. - TroitiÑo, M. (2007), Lo que han traído las olas. Una historia de surf en Zarautz, Zarautz: Ayuntamiento de Zarautz, Dirección de Cultura.

Elias, N. - Dunning, E. (1992), Deporte y ocio en el proceso de civilización, Madrid: F.C.E.

Esparza, Daniel (2010), «Los orígenes del surfing en Málaga», Jábega, Revista de la Diputación Provincial de Málaga 102, 115-129.

Esparza, Daniel (2011), «De Hawai al Mediterráneo: La génesis del surf en España», Revista Internacional de Ciencias del Deporte 26, 370-383.

Finney, B. - Houston, J. (1996), Surfing: A History of the Ancient Hawaiian Sport, San Francisco: Pomegranate Artbooks.

GARDINIER, Alain (2004), Les Tontons Surfeurs, Anglet: Atlántica.

Gonfaus, Alain (2006), Una visión antropológica de la cultura del surf, San Sebastián: Zoe.

MAOZ, Z. - RussetT, B. (1993), «Normative and structural causes of democratic peace 1946-1986», American Political Science Review 87 (3), 624-638.

Pellón, José (ed.) (2009), Historia del surfing en Cantabria (1963-2009), Santander: Cantabria Tradicional.

RAY, J. (1993), «Wars between democracies: rare, or nonexistent», International Interactions 18 (3), 251-276.

WALKER, Isaiah Helekunihi (2011), Waves of Resistance: Surfing and History in the Twentieh-Century Hawai'i, Honolulu: University of Hawai'i Press.

Lista de todos los artículos de prensa hallados (ordenados por orden cronológico)

1. «Un nuevo deporte acuático: los montadores de olas». La Vanguardia Española, 5-9-1911, p. 10.

2. (Sin título). El Mundo Deportivo, 29-10-1926, p. 2.

3. «Notas del Extranjero: Los Ángeles. Deporte Americano». La Vanguardia Española. 29-10-1929, p. 2.

4. «El último film de Douglas Fairbanks». La Vanguardia Española. 24-11-1931, p. 18.

5. Assia, Augusto. «La vuelta al mundo: en Honolulú». La Vanguardia Española. 6-71949 , p. 5.

6. «Paraíso de las vacaciones felices: La Costa vasca francesa». ABC (Blanco y Negro), 14-4-1962, p. 72.

7. Quesada, Jaime. «Los 〈barcos voladores〉 entre San Sebastián y Biarritz». La Vanguardia Española. 8-2-1964, p. 8.

8. «De Biarritz a San Juan de Luz, o de Napoleón III a Luis XIV». ABC (Blanco y Negro), 23-5-1964, p. 113.

9. «Ride the Wild Surf» (Cabalgando sobre las olas). 8-6-1964. El Mundo Deportivo, p. 11.

10. Pardo, Carlos. «El Surfing, un gran deporte que el Cantábrico podría adoptar». El Mundo Deportivo, 17-8-1964, p. 5.

11. «Honolulu: El deporte del surf». La Vanguardia española, 19-9-1965, p. 38.

12. Pardo, Carlos. «El Surf o el Deporte de las Olas». El Mundo Deportivo, 13-1-1966, p. 8.

13. «El Surf, un deporte de Moda». ABC, (Blanco y Negro), 23-7-66, p. 16.

14. «El Surf ha llegado al norte de España». ABC, (Blanco y Negro), 10-9-1966. p. 83. 
15. «Primer contacto con África del Sur». La Vanguardia Española, 15-10-1966, p. 52.

16. «Beach Boys». Marca, 15-1-1967, p. 12.

17. «Los Peligros del Surf». Marca, 10-8-1967, p. 5.

18. «Biarritz, después...». ABC (Madrid), 4-11-1967, p. 48.

19. «Falleció el inventor del «crawl»: El hawaiano Kahanamoku, una figura legendaria de la natación». El Mundo Deportivo, 24-1-1968, p. 25.

20. «Australia el continente más joven y con futuro más prometedor». La Vanguardia Española, 2-4-1968, p. 45.

21. Gorgojo, Emilio. «El surf, un deporte que se abre paso en España». As, 10-41969, p. 21.

22. «El alcalde de Zarauz habla del surf y deportes de playa». As, 26-4-1969, p. 21.

23. «Campeonato de Surf en la playa de Zarauz». ABC (Blanco y Negro), 30-8-1969, p. 16-17.

24. «Santander, escenario del primer campeonato de España de Surf». ABC, 15-81970, p. 48.

25. «El Surf llegó a Zarauz». Marca, 20-8-1970, p. 14.

26. «Campeonato Español de Surf». El Mundo Deportivo, 20-8-1970, p. 10.

27. «Primer Campeonato de España de Surf». El Mundo Deportivo, 22-8-1970, p. 10.

28. Criado, Eduardo. «Viaje a las Islas Hawai: Ese deporte llamado Surf». La Vanguardia Española, 3-9-1970, p. 38.

29. «Jesús Fiochi quedó séptimo en el Campeonato Internacional de Francia». Marca, 8-10-1970, p. 12.

30. «El Surf, un nuevo deporte que se abre camino en España». Marca, 8-11-1970, p. 11.

31. «En España hay diez clubs de surf». El Mundo Deportivo, 11-11-1970, p. 21.

32. «El Surf es un deporte en auge». La Vanguardia Española, 11-11-1970, p. 60.

33. «Aprendizaje y dureza del esquí acuático». ABC (Blanco y Negro), 26-6-1971, p. 90.

34. «Fiochi y Campa triunfaron en Baquio». Marca, 19-7-1971, p. 18.

35. Pardo, Carlos. «El Surf: Deporte de las olas». El Mundo Deportivo, 26-7-1971, p. 27

36. «Francia-España de Surf». El Mundo Deportivo, 28-7-1971, p. 20.

37. «El Surf nace en España como deporte de verano». La Vanguardia Española, 307-1971, p. 35.

38. Pardo, Juan. «Nuevo deporte: el casi increíble 〈pequeño〉surf». La Vanguardia Española, 7-10-1971, p. 59.

39. «Los mejores surfistas de España son los Santanderinos». As, 13-12-1971. p. 2-23.

40. «Un deporte en embrión, el surf» (Rueda de Prensa en INEF). As, 15-12-1971, p. 29.

41. «Campeones de Surf». Marca, 16-12-1971, p. 14.

42. «El Surf, un deporte en alza». La Vanguardia Española, 23-12-1971, p. 72.

43. «Diez deportistas santanderinos aspirantes al Alerta de Plata». As, 24-12-1971, p. 23.

44. «La Patinadora Cionín Villagra, mejor deportista santanderina de 1971». La Vanguardia Española, 11-1-1972, p. 54.

45. «Sobre Margarita de Dinamarca». ABC, 16-1-1972, p. 127. 
46. «El Campeonato de España de Surf». El Mundo Deportivo, 7-9-1972, p. 14.

47. «Suspensión del Campeonato de España de Surf». El Mundo Deportivo, 14-91972, p. 31.

48. «Dos muchachos desaparecen en el mar». La Vanguardia Española, 31-5-1972, p. 11.

48b. «Dos jóvenes vizcaínos perecen arrastrados por una ola mientras se bañaban». ABC, 31-5-1972, p. 43.

49. Biescas Vignau, Alfonso. «El Surf: Un regalo de la Naturaleza». La Vanguardia Española, 5-7-1972.

50. «16 clubs y 356 federados, en la temporada anterior». Marca, 31-5-1973, p. 27.

51. Vila, S. «El Surf toma incremento en España». La Vanguardia Española, 8-6-1973, p. 70.

52. Areilza, José María de. «La Mar». La Vanguardia Española, 24-6-1973, p. 13.

53. «Los peligros del surf». Marca, 22-7-1973, p. 31.

54. «Actividad en los puestos de socorro playas vizcaínas». ABC, 12-9-1973, p. 40

55. «Siempre hay una razón más para conocer Canarias». ABC, 23-6-1974, p. 133.

56. «Siempre hay una razón más para conocer Canarias». La Vanguardia Española, 10-7-74, p. 51.

57. «Entrevista a Rocío Durcal». Marca, 22-9-74, p. 17.

\author{
Daniel Esparza \\ Katedra romanistiky \\ Filozofická fakulta \\ Univerzita Palackého v Olomouci \\ Křížkovského 10 \\ 77180 Olomouc \\ República Checa \\ daniel.esparza@upol.cz
}

